\title{
Laser assisted micro grinding of high strength materials
}

\author{
W Chang ${ }^{1, \text { a }}$, X Luo $^{1, \mathrm{~b}}, \mathrm{Q}$ Zhao $^{2, \mathrm{c}} \mathrm{J} \mathrm{Sun}^{1, \mathrm{~d}}$ and $\mathrm{Y}$ Zhao $^{2, \mathrm{e}}$ \\ ${ }^{1}$ Heriot-Watt University, Edinburgh EH14 4AS, UK \\ ${ }^{2}$ Center for precision Engineer, Harbin Institute of Technology, China \\ awc129@hw.ac.uk, bx190@hw.ac.uk, 'zhaoqingliang@hit.edu.cn, \\ djs173@hw.ac.uk, eluobo4423362@163.com
}

Keywords: Laser assisted grinding, Hybrid process, Micro grinding, Subsurface damage

\begin{abstract}
.
This paper aims to develop a laser assisted grinding process capable of manufacturing micro features in high strength materials. A diode laser with wavelength $808 \mathrm{~nm}$ was set on a precision grinding machine. Micro grooves were fabricated on high strength materials including silicon nitride and aluminium oxide by using the laser assisted grinding process, i.e. laser pre-heat workpiece flowed by micro grinding. The experimental results showed that the laser assisted grinding process resulted in deeper grooves due to thermal expansion of workpiece materials caused by laser heating. However, the machined surface roughness was more consistently better than that obtained using solo grinding process and applying coolant. No subsurface damage was observed in the SEM images of cross sections of the machined workpieces when laser assisted grinding process was used.
\end{abstract}

\section{Introduction}

High strength materials, including silicon nitride $\left(\mathrm{Si}_{3} \mathrm{~N}_{4}\right)$ and aluminium oxide $\left(\mathrm{Al}_{2} \mathrm{O}_{3}\right)$, are widely used in the application of highly stressed components. Due to high hardness of such workpiece materials, conventional machining approached such as grinding and milling suffer from low machining efficiency and high tool wear which will affect the attainable fine surface quality. Yang [1] found the laser heating could improve the machinability of silicon nitride ceramics through reducing cutting force, increasing tool life and reducing workpiece edge chipping. Melkote [2] and Brecher [3] presented laser assisted milling which can obtain much better surface roughness. Singh [4] investigated the impact of laser power, spot size and speed to reduce cutting force and tool deflections when fabricating hard-to-machine materials. Laser assisted milling/turning processes have been studied in many researches but very limited work has been reported on laser assisted grinding processes [5].

This paper presents an experimental study of the laser assisted micro grinding process. A diode laser system has been integrated into a grinding machine. Experiments have been carried out on the machine to investigate laser assisted micro grinding process on materials including $\mathrm{Si}_{3} \mathrm{~N}_{4}$ and $\mathrm{Al}_{2} \mathrm{O}_{3}$. The grooves dimension, grinding force, surface roughness, microstructure of machined surface and subsurface damage are also discussed in this study. 


\section{Experiment setup}

The experimental equipments of laser assisted micro grinding are shown in Fig 1. The grinding machine (MUGK7120X5) consists of servo motors on the $\mathrm{X}$ and $\mathrm{Z}$ axes and a linear motor on the $\mathrm{Y}$ axis. A variable high speed spindle (SF3060-ST32) with rotational speeds up to $60,000 \mathrm{rpm}$ and laser focus lens were fixed on the grinding machine. A $3 \mathrm{~mm}$ diameter grinding cutter with grit size of $70-80 \mu \mathrm{m}$ was used in the experiment. The thickness of diamond layer was about $0.3 \mathrm{~mm}$ and the length was $15 \mathrm{~mm}$. The diode laser power was up to $120 \mathrm{~W}$ and wavelength was $808 \mathrm{~nm}$. The spot size was near $3.2 \mathrm{~mm}$ on the focus point and the distance between the focus point and the grinding cutter was about $10 \mathrm{~mm}$. The workpiece was fixed on a small vice which was attached on a Kistler dynamometer (9256C). Two kinds of materials, $\mathrm{Si}_{3} \mathrm{~N}_{4}$ and $\mathrm{Al}_{2} \mathrm{O}_{3}$, were investigated in this experiment. A nozzle with air assisting was used to blow grinding cutter on the $\mathrm{Y}$ axis.

In the experiments, three grooves were machined on each material. First groove was fabricated by traditional grinding approach with soluble oil coolant. Second groove was machined by using laser assisted grinding and air coolant on the grinding cutter. Final groove was manufactured by laser assisted grinding without applying any coolant. The spindle speed, feedrate and cutting depth were $10,000 \mathrm{rpm}, 10 \mathrm{~mm} / \mathrm{min}$ and $3 \mu \mathrm{m}$, respectively. The laser power was set to $45 \mathrm{~W}, 70 \mathrm{~W}$ on material of $\mathrm{Si}_{3} \mathrm{~N}_{4}$ and $\mathrm{Al}_{2} \mathrm{O}_{3}$.

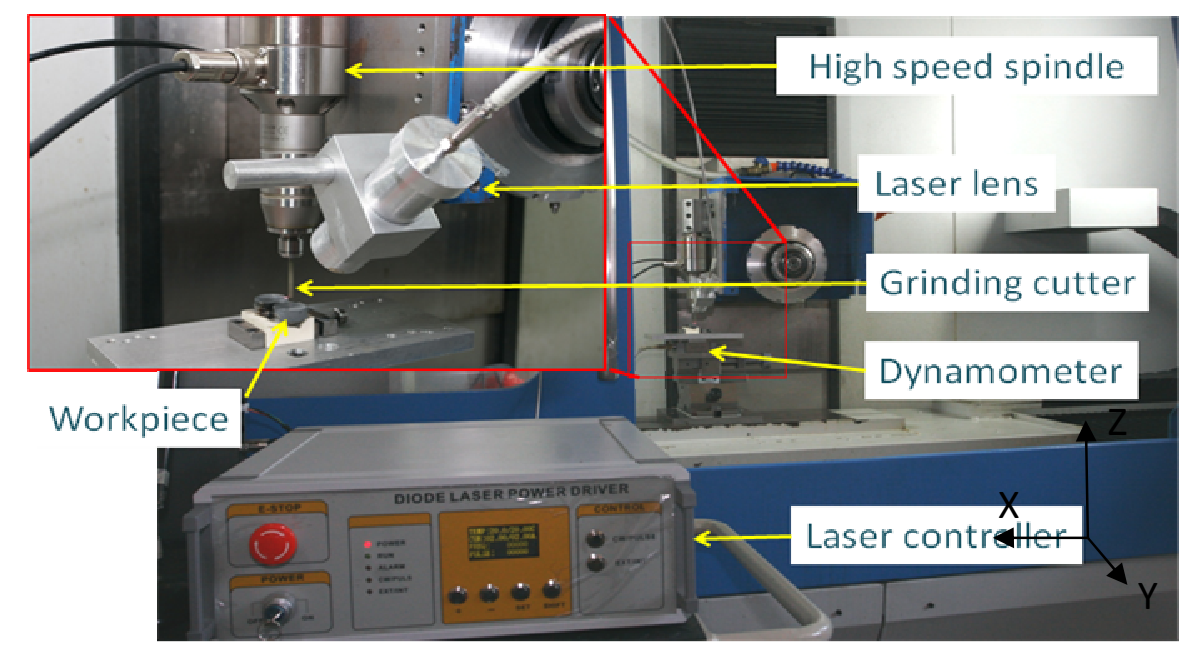

Fig 1. Experiment system of laser assisted grinding

\section{Results and discussions}

Groove depth

The variation in groove depth measured by a Form Talysurf (Taylor-Hobson Talysurf 4-120) is shown in Fig 2. It shows that the groove depth is relatively close to the set depth $3 \mu \mathrm{m}$. When laser assisted process was used, the groove depth was higher due to thermal expansion. In addition, the thermal expansion of the tool and the workpiece during laser heating affect the accuracy of the groove depth. The grinding depth manufactured by using laser assisted grinding with air coolant 
was between the cutting depth machined by using conventional grinding process and laser assisted process. The workpiece was heated by laser assisted process but the air coolant counteracted such an effect and kept the temperature constant.

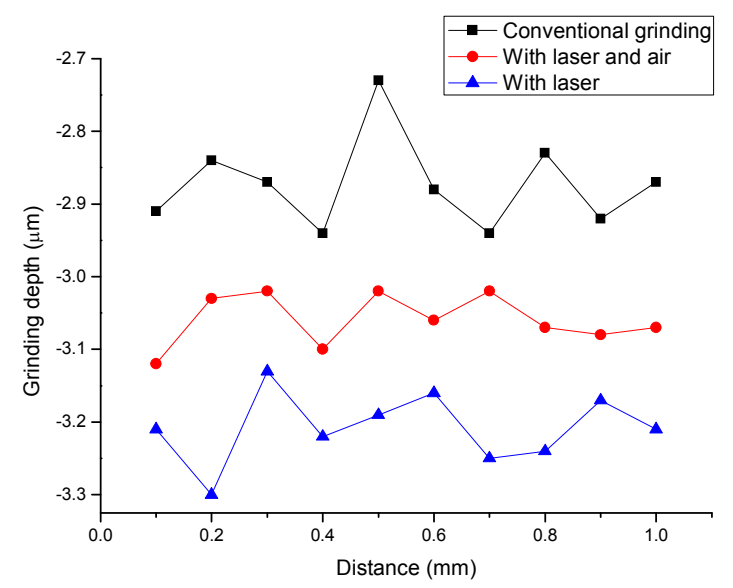

(a) $\mathrm{Si}_{3} \mathrm{~N}_{4}$

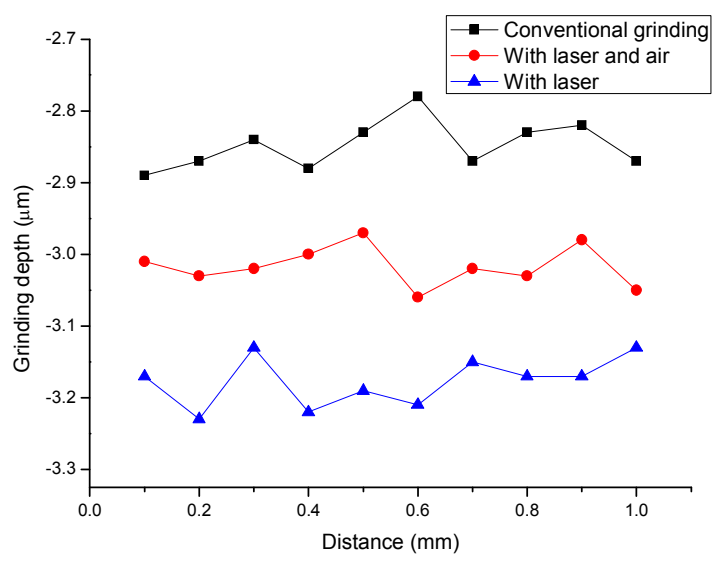

(b) $\mathrm{Al}_{2} \mathrm{O}_{3}$

Fig 2. Groove depth on the middle surface cross the machining direction

\section{Grinding force}

The grinding force on $\mathrm{Si}_{3} \mathrm{~N}_{4}$ measured by Kistler dynamometer is shown in Fig 3. The grinding force in conventional grinding process was smoother than that by using laser assisting grinding. The grinding force of laser assisted grinding without air coolant was very close to the conventional machining process, especially in the end of the grinding process. The largest grinding force was found when both the laser and air coolant were used. Under this circumstance, the grinding force varied greatly along the machining distance. This was because when the laser assisted grinding was used, the strength of material was decreased by the rise of the temperatures on the workpiece. Material with lower strength is much easier to be removed. However, the air coolant decreased temperature and the larger grinding force was presented. The average grinding force of conventional grinding process, with laser and with laser and air coolant were $3.51 \mathrm{~N}, 3.87 \mathrm{~N}$ and $9.54 \mathrm{~N}$, respectively.

Surface roughness and microstructure of the machined surface

The surface roughness $\mathrm{Ra}$ on $\mathrm{Si}_{3} \mathrm{~N}_{4}$ is shown in Table 1. They were measured by both a white light interferometer (Zygo New View 5000) and an AFM (DI NanoScope IIIa). The average surface roughness of conventional grinding, laser assisted grindings using air coolant and without using coolant were $202.594 \mu \mathrm{m}, 334.599 \mu \mathrm{m}$ and $139.923 \mu \mathrm{m}$, respectively. These two measured results showed that in terms of surface roughness, the quality of the machined surface can be greatly improved by the laser assisted grinding process. 
The microstructure of the machined surface was measured by the AFM. The measured surface topographies are shown in Fig 4. and Fig 5. Large crest and trough could be observed on the machined surface obtained by using conventional grinding process. However, small grain size on the machine surface is observed in both Fig 4 (b) and Fig 5 (b) when laser assisted grinding was used. The microstructure of the machined surface on both materials showed that smooth surface crest and trough could be obtained when the laser assisted grinding processes was used.

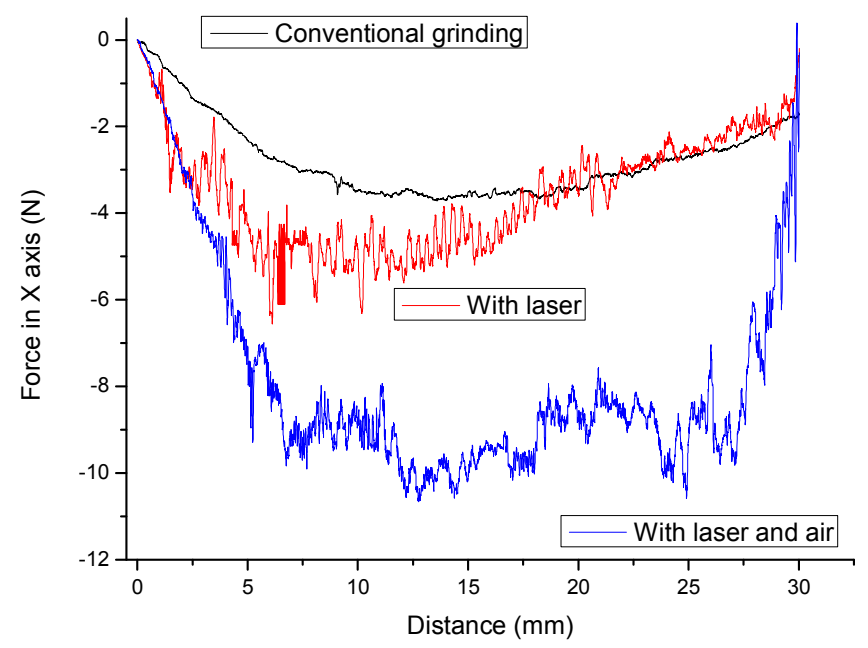

Fig 3. The grinding force against cutting distance

Table 1 Surface roughness on $\mathrm{Si}_{3} \mathrm{~N}_{4}$

\begin{tabular}{|l|c|c|c|c|}
\hline \multicolumn{1}{|c|}{ Surface roughness Ra } & \multicolumn{3}{|c|}{ White light interferometer $[\mu \mathrm{m}]$} & AFM $[\mu \mathrm{m}]$ \\
\hline Conventional grinding & 182.543 & 225.197 & 200.041 & 164.43 \\
Laser assisted grinding and air coolant & 353.432 & 317.939 & 332.425 & 294.32 \\
Laser assisted grinding & 111.546 & 173.448 & 134.776 & 112.85 \\
\hline
\end{tabular}

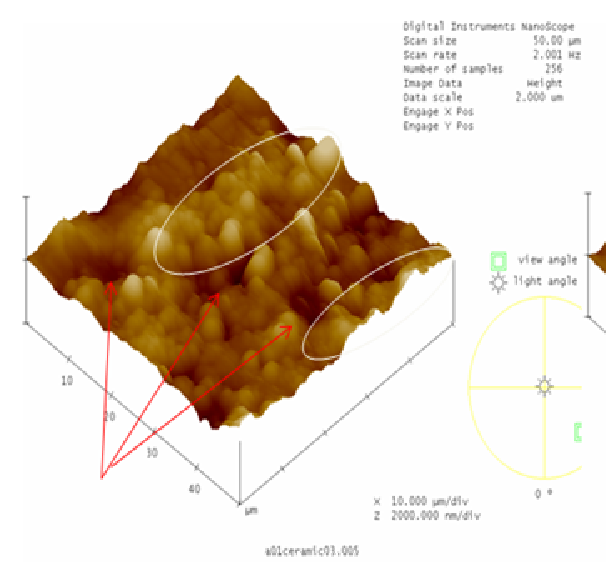

(a)Conventional grinding

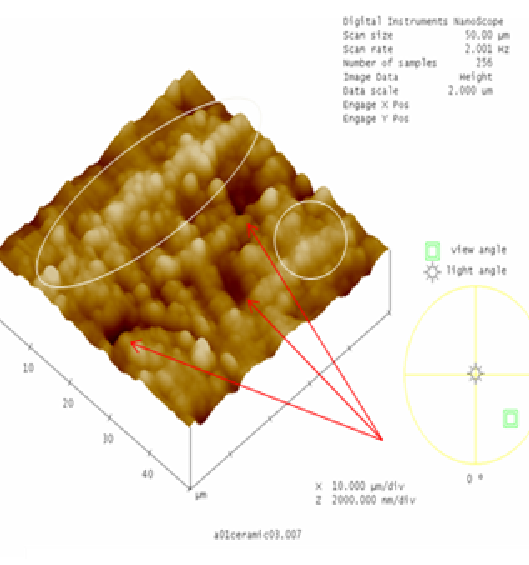

(b)Laser assisted grinding

Fig 4. The $3 \mathrm{D}$ structure of $\mathrm{Si}_{3} \mathrm{~N}_{4}$ 


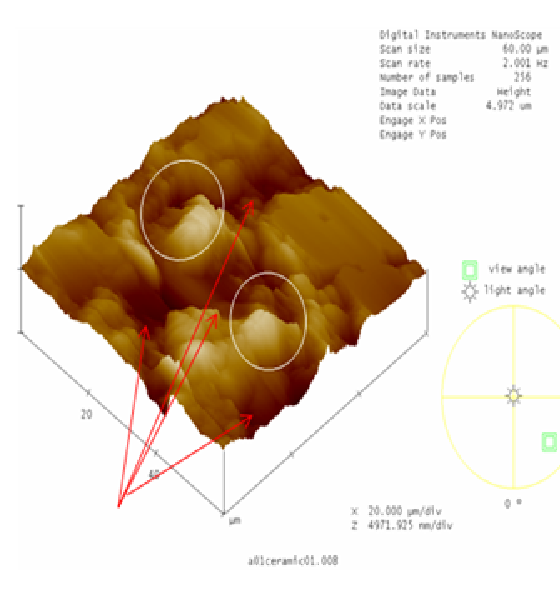

(a)Conventional grinding

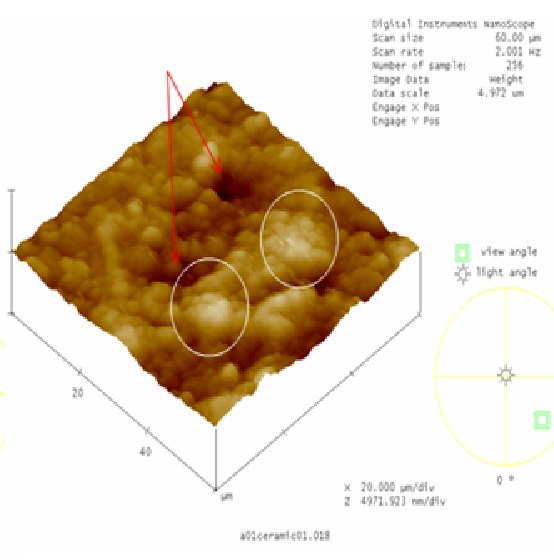

(b)Laser assisted grinding

Fig 5. The 3D structure of $\mathrm{Al}_{2} \mathrm{O}_{3}$

\section{Subsurface damage}

The workpiece was coated $2 \mathrm{~nm}$ gold on the top surface before testing subsurface damage. The cross sections were obtained on a focused ion beam system (FEI Quanta 3D FEG) and observed by a SEM built inside the FIB system. In each test region, cross sections with dimensions of $5 \mu \mathrm{m} \times 5$ $\mu \mathrm{m} \times 5 \mu \mathrm{m}$ were milled under a beam current of $7 \mathrm{nA}$. The subsurface damage on $\mathrm{Si}_{3} \mathrm{~N}_{4}$ after conventional grinding is shown in Fig 6(a). It could be seen that the material was compressed. Some small cracks were observed on $\mathrm{Si}_{3} \mathrm{~N}_{4}$ after laser assisted grinding with air coolant applied. As shown in Fig 7 (a) the cracks were about $2 \mu \mathrm{m}$ long on $\mathrm{Al}_{2} \mathrm{O}_{3}$ when conventional grinding was used. Some large cracks on $\mathrm{Al}_{2} \mathrm{O}_{3}$ were also seen when laser assisted grinding with air coolant was used. However it was barely to see subsurface damage on both materials when the laser assisted grinding process without using any coolant was used.

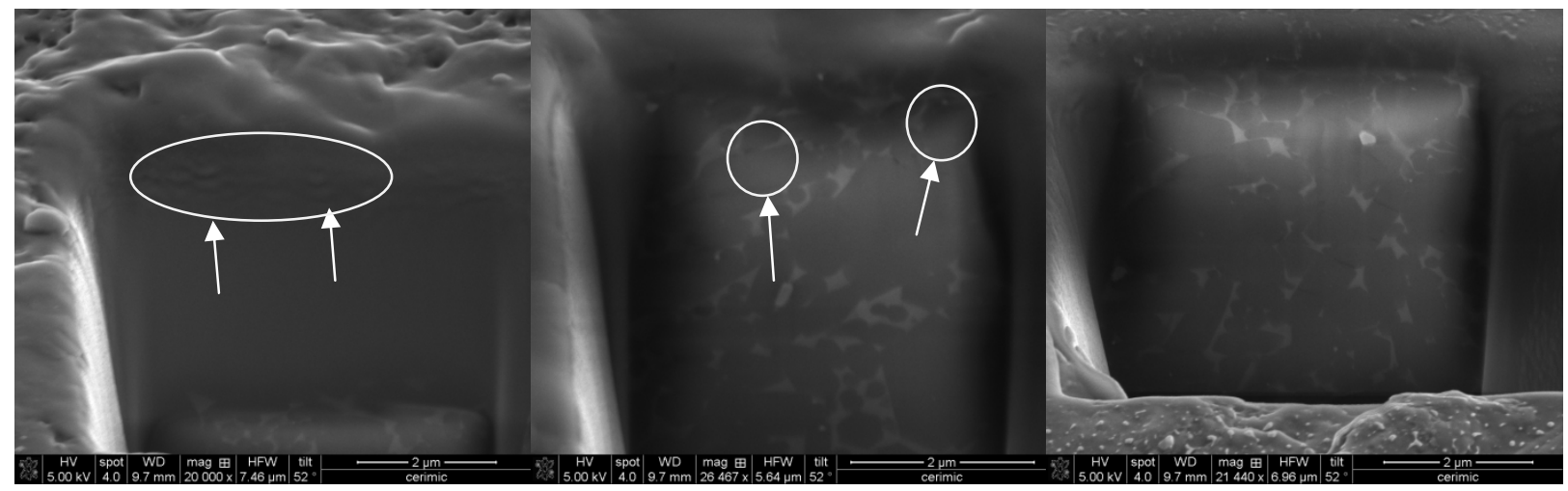

(a)Conventional grinding (b) Laser assisted grinding with air coolant (c) Laser assisted grinding

Fig 6. Subsurface damage on $\mathrm{Si}_{3} \mathrm{~N}_{4}$ 


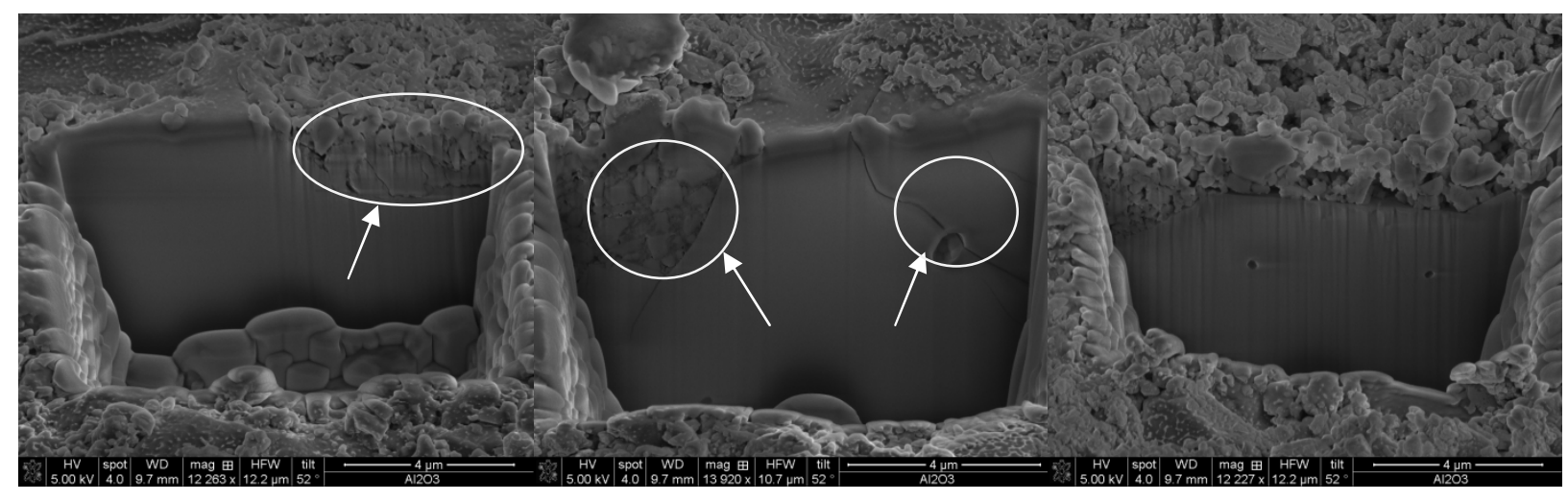

(a)Conventional grinding (b) Laser assisted grinding with air coolant (c) Laser assisted grinding

Fig 7. Subsurface damage on $\mathrm{Al}_{2} \mathrm{O}_{3}$

\section{Conclusion}

This research carried out experimental study on laser assisted grinding approach to machine hard-to-machine materials. The results showed that the laser assisting grinding achieved almost the same grinding depth as that in conventional grinding process. Although the grinding force were nearly the same as that in conventional grinding better surface roughness was achieved when the laser assisted process was applied. There was no subsurface damage obtained by using laser assisted grinding approach. This hybrid process will be very useful to fabricate brittle materials such as $\mathrm{Si}_{3} \mathrm{~N}_{4}$ and $\mathrm{Al}_{2} \mathrm{O}_{3}$.

\section{References}

[1] B. Yang and S. Lei, in: Int. J. Mechatronics and Manufacturing System. Vol. 1 (2008), p. 116

[2] S. Melkote, M. Kumar, F. Hashimoto and G. Lahoti, in: CIRP annals - Manufacturing Technology. Vol. 58 (2009), p. 45

[3] C. Brecher, M. Emonts, C.J. Rosen and J.P. Hermani, in: Physics Procedia. Vol. 12 (2011), p. 599

[4] R. Singha and S.N. Melkote, in: Int. J. of Machine Tools and Manufacture. Vol. 47 (2007), p. 1139

[5] E. Westkamper, in: CIRP annals - Manufacturing Technology. Vol. 44 (1995), p. 317 


\section{Precision Machining VI}

10.4028/www.scientific.net/KEM.496

\section{Laser Assisted Micro Grinding of High Strength Materials}

10.4028/www.scientific.net/KEM.496.44

\section{DOI References}

[1] B. Yang and S. Lei, in: Int. J. Mechatronics and Manufacturing System. Vol. 1 (2008), p.116. doi:10.1504/IJMMS.2008.018282

[2] S. Melkote, M. Kumar, F. Hashimoto and G. Lahoti, in: CIRP annals - Manufacturing Technology. Vol. 58 (2009), p.45.

http://dx.doi.org/10.1016/j.cirp.2009.03.053

[3] C. Brecher, M. Emonts, C.J. Rosen and J.P. Hermani, in: Physics Procedia. Vol. 12 (2011), p.599.

doi:10.1016/j.phpro.2011.03.076

[4] R. Singha and S.N. Melkote, in: Int. J. of Machine Tools and Manufacture. Vol. 47 (2007), p.1139. http://dx.doi.org/10.1016/j.ijmachtools.2006.09.004

[5] E. Westkamper, in: CIRP annals - Manufacturing Technology. Vol. 44 (1995), p.317.

http://dx.doi.org/10.1016/S0007-8506(07)62333-6 